\title{
Experiências de políticas em alimentação e nutrição
}

SEMÍRAMIS MARTINS ÁLVARES DOMENE, ROSANA RODRIGUES LEMES OTA, EDUARDO AUGUSTO FER NANDES NILSON, MIRIAM IZABEL SIMÕES OLLERTZ, TEREZA TOSHIKO WATANABE e PAULO RogÉRIO GALLO

\section{Introdução}

$\mathrm{M}$ edidas de combate à fome e à desnutrição foram estudadas por diversos autores, que se dedicaram a registrar a história das políticas nacionais na área de alimentação e nutrição (Musgrove, 1990; Vasconcelos, 2005) e o impacto de programas específicos, como o Programa Nacional de Alimentação Escolar (PNAE) (Mazzilli, 1987; Spinelli \& Canesqui, 2002; Ometto et al., 2003) ou o Programa de Alimentação do Trabalhador (PAT) (Burlandy \& Anjos, 2001; Veloso \& Santana, 2002; Savio et al., 2005), entre outros de menor duração.

As contribuições da literatura sobre o tema invariavelmente incluem em sua abordagem a necessária análise do contexto social das famílias ou dos indivíduos atendidos pelos programas que compõem a política vigente (Campino, 1985). Nesse sentido, a associação da fome com a pobreza ganha destaque (Castro, 2004) e mostra como o enfrentamento do problema depende de políticas estruturantes combinadas com ações emergenciais de combate à fome imediata, ainda necessárias (Vasconcelos, 2005).

Esse entendimento cresceu não apenas na academia e no Estado, mas igualmente na sociedade, levando o tema da segurança alimentar e nutricional para a agenda de governantes no Brasil e em outros países, os quais se mobilizam para buscar estratégias de combate à carência de alimentos e seus efeitos (Domene, 2003).

Os desafios para equacionar o desnível social, que cria obstáculos à democratização das oportunidades (Castro et al., 2004) e expõe um grande contingente de cidadãos a situações de risco, podem, contudo, comprometer propostas de caráter genérico, sobretudo se concebidas de maneira isolada e desconsiderando o contexto em que a má nutrição ocorre.

Algumas ações bem-sucedidas, desenvolvidas com mecanismos de acompanhamento, indicam caminhos possíveis e serão apresentadas a seguir. O conhecimento dessas experiências - e especialmente dos limites operacionais que encon- 
traram - deve orientar os passos para o aprimoramento de programas e políticas da área, de forma a otimizar os recursos públicos destinados à sua manutenção.

\section{PNAE e PAT-Dois ícones entre as políticas públicas de alimentação e nutrição}

A alimentação escolar merece destaque entre as políticas públicas nacionais na área de alimentação não apenas por sua duração - em 2005 completou cinqüenta anos de existência -, mas especialmente por sua abrangência, resultado da criação, em 1979, do Programa Nacional de Alimentação Escolar (PNAE), atualmente presente em 5.560 municípios dos 27 Estados da federação, atendendo cerca de 36 milhões de escolares do ensino infantil e fundamental. Para esse segmento, a União repassa aos municípios $\mathrm{R} \$ 0,18$ centavos por aluno/dia, para que a unidade executora proceda à compra de gêneros alimentícios. $\mathrm{O}$ financiamento se estende também a estudantes indígenas e quilombolas, para os quais o valor é de R\$ 0,34 centavos por dia.

Dessa forma, atende-se ao disposto na Constituição Federal de 1988, que trata em seu artigo 208 da alimentação como direito do escolar. ${ }^{1}$

Outra política de alimentação com destaque comparável ao PNAE é o Programa de Alimentação do Trabalhador (PAT), que completou 25 anos em 2002, atendendo oito milhões de trabalhadores em 103 mil empresas em todo o Brasil (Mazzon, 2001, apud Savio et al., 2005). A literatura nacional tem registros de avaliações do programa, especialmente quanto aos objetivos de ordem nutricional (Burlandy \& Anjos, 2001; Veloso \& Santana, 2002), e não trataremos dessa política.

\section{A modernização do PNAE}

O ganho de eficiência de qualquer política de longa duração exige mudanças conceituais na forma de planejar as ações, a fim de que sua execução se ajuste às transformações da sociedade. Hoje, pode-se afirmar que houve a superação de um modelo assistencialista apoiado na transferência de recursos de um programa para outro, e a alimentação, vista como direito humano, é tratada na escola com participação da sociedade civil e com garantia do controle social.

Essa modernização traz ao PNAE reconhecimento como um dos maiores programas na área de alimentação escolar do mundo, haja vista atender todos os alunos matriculados na Educação Infantil e no Ensino Fundamental das escolas públicas e filantrópicas de todo o país, além de mais recentemente ter estendido esse atendimento aos escolares indígenas e das comunidades quilombolas (Resolução n⿳0 45 de 31.10.2003, 38 de 29.08.2004, e Resolução no 21 de 27.5.2005, alteradas pela Resolução n⿳0 32 de 10.8.2006).

Outros sinais de amadurecimento da concepção do PNAE podem ser percebidos pela transferência da responsabilidade, antes centralizada, para um sistema do qual participam os três entes federados - União, estados e municípios -, que agora fazem a gestão integrada de um programa suplementar à educação, e não apenas de alocação de recursos financeiros. 
Essa forma de gestão visa garantir os princípios de universalidade, continuidade e descentralização, além de promover a participação social, para que se alcance um atendimento equânime. As diretrizes do projeto procuram respeitar os hábitos regionais e a vocação agrícola de cada municipalidade, e, por meio do estímulo ao exercício do controle social, acompanhar as ações de todos os parceiros da gestão, a fim de assegurar a oferta de alimentação de boa qualidade a todos os escolares, para o suprimento de $15 \%$ de suas necessidades nutricionais diárias.

Tais ações contribuem para a promoção do crescimento e do desenvolvimento do escolar, para o processo de ensino-aprendizagem, para a formação de hábitos alimentares saudáveis e, ainda, para a dinamização da economia local, por meio de geração de emprego e renda em setores dirigidos à produção, ao transporte e ao processamento dos alimentos.

Os desafios advindos desse compromisso, entretanto, são proporcionais aos benefícios esperados.

Inicialmente, há uma demanda reconhecida para qualificação de gestores e Conselhos de Alimentação Escolar (CAE), que garantem a aplicação dos recursos exclusivamente no programa. Parte da efetividade de sua ação depende da construção de uma legislação simplificada e completa; a revisão do texto de algumas resoluções do Fundo Nacional de Desenvolvimento da Educação (FNDE), autarquia federal vinculada ao Ministério da Educação que gerencia o PNAE, é uma ação concreta que sinaliza avanços nessa área.

Outras medidas estratégicas advirão dos dados de um estudo nacional a ser iniciado em 2006. A adoção de medidas que respeitem as externalidades negativas, como são denominadas por Torres \& Marques (2004) as características locais que contribuem para o fracasso de políticas nacionais, é um ponto-chave para o sucesso dessas políticas.

A presença de nutricionistas que possam efetivamente acompanhar o programa em todas as municipalidades é uma meta que trará subsídios também para o monitoramento e a avaliação da execução do PNAE, além de viabilizar a implantação de um programa de educação nutricional e alimentar nas escolas e, eventualmente, do monitoramento nutricional.

\section{Medidas já incorporadas à gestão do PNAE}

Os processos que já foram iniciados com o objetivo de atender às metas citadas incluem:

- a reavaliação de princípios, diretrizes e objetivos atuais do Programa;

- o preparo do Sistema InfoCAE para cadastramento on-line e aprimoramento da relação entre CAE e FNDE;

- o planejamento da pesquisa nacional de consumo e do perfil nutricional dos escolares atendidos pelo Programa, financiados pelo MCT/Finep; a fiscalização conjunta com a Controladoria Geral da União (CGU) e o Ministério Público; a participação no Conselho Federal de Nutricionistas e nos conselhos regionais de nutrição; 
- a realização de eventos nacionais e regionais de capacitação de conselheiros; e a divulgação do Programa em eventos internacionais, em busca de troca de experiências.

No que se refere ao monitoramento da gestão, cidadãos e gestores podem obter na página do Fundo Nacional de Desenvolvimento da Educação (FNDE) (www.fnde.gov.br/home/index.jsp) os dados para contato. O estímulo ao fortalecimento do controle social se dá por meio da garantia de formas de participação via audiências públicas e programas de capacitação oferecidos aos conselhos de alimentação escolar.

Todo esse conjunto de ações está sendo constantemente acompanhado, com vistas a fortalecer o PNAE.

\section{Políticas recentes: o Bolsa Alimentação}

Estratégias de combate à pobreza por meio da adoção de programas de transferência de renda com condicionalidades foram experimentadas em um grande número de governos. O Brasil criou diversos programas federais a partir da década de 1990, tais como o Programa Bolsa Escola, o Bolsa Alimentação, o Programa de Erradicação do Trabalho Infantil e o Vale-Gás.

O Programa Bolsa Alimentação foi criado em 2001 como Programa de Renda Mínima vinculado à Saúde, tendo como principal objetivo reduzir a desnutrição infantil por meio da transferência mensal de R\$15,00 por beneficiário, identificado como cidadão de baixa renda e em risco nutricional. Os beneficiários potenciais do programa eram crianças de até sete anos de idade, gestantes e nutrizes, cujas famílias se comprometiam a uma agenda positiva de saúde, a qual englobava o acompanhamento do crescimento e desenvolvimento das crianças, a imunização de crianças e gestantes e a participação em ações educativas de saúde e nutrição. O programa, quando implantado em todos os 5.561 municípios brasileiros, pretendia atender 2,7 milhões de crianças e aproximadamente oitocentas mil gestantes e nutrizes.

Os programas de transferência de renda têm como um de seus principais objetivos o combate à fome que está associada à pobreza. A melhoria das condições de vida dessas famílias, especialmente em sua alimentação, comporta um grande potencial de melhora dos indicadores nutricionais, o que constitui parte da lógica que vincula as estratégias de transferência de renda para famílias mais pobres à nutrição de suas crianças.

Experiências recentes de alguns países latino-americanos, como o Programa de Educación Y Salud (Progresa), do México, trazem evidências dos potenciais impactos da transferência de renda sobre os gastos com alimentos e sobre a qualidade nutricional da dieta das famílias.

Não se pode, contudo, acreditar que esses programas levem rapidamente à melhoria do bem-estar das famílias e à redução da pobreza, se não forem acompanhados do fortalecimento de práticas saudáveis, especialmente quanto ao cuidado da criança. Isso levou à proposta de associar ao benefício o compro- 
misso da família com ações desejáveis, como o cumprimento de calendário de vacinação.

\section{Avaliação de impacto}

Na tentativa de estimar o impacto do programa, beneficiários (crianças, gestantes ou nutrizes com renda familiar per capita inferior a R\$ 90,00) foram pareados e comparados com indivíduos elegíveis de domicílios que não haviam sido incluídos no programa, em decorrência de erros experimentados com a implantação das primeiras versões do cadastro (tais como separação acidental de arquivos ou preexistência de cadastro com informações conflitantes sobre uma mesma família). Os dados socioeconômicos e demográficos das famílias estão na Tabela 1.

\section{Tabela 1}

Características socioeconômicas e demográficas das famílias dos estudos de avaliação do Programa Bolsa Alimentação (2003)

Beneficiárias Controle

Número de pessoas na família

Renda per capita inferida $(\mathrm{R} \$)$

Chefes alfabetizados

Famílias com crianças entre 0 e 7 anos

Famílias com crianças entre 7 e 15 anos
5,66

75,89

$35,8 \%$

$95,9 \%$

$59,1 \%$

\section{5,55}

71,06

$36,6 \%$

$87,2 \%$

$78,7 \%$

A amostra da avaliação foi constituída por meio do pareamento de famílias beneficiárias e não-beneficiárias da bolsa alimentação, pertencentes a quatro municípios localizados na região Nordeste, onde se encontravam $60 \%$ dos beneficiários do programa. São eles: Teotônio Vilela (AL), Mossoró (RN), Itabuna e Teixeira de Freitas (BA). Os dados foram coletados após seis meses de transferência de renda (com 869 famílias), e posteriormente, no ano de 2003, com dois anos de transferência (com 743 famílias).

Os levantamento antropométrico e os dados sobre consumo alimentar, acesso e demanda por serviços de saúde e crescimento infantil mostraram o impacto positivo do programa, como se descreve a seguir.

\section{Propensão Marginal ao Consumo de Alimentos (PMCA)}

Esse indicador econométrico representa o porcentual de cada unidade monetária transferida que é usado para a compra de alimentos. O PMCA variou, aos seis meses de transferência, entre $55 \%$ e $74 \%$, valores maiores do que os encontrados em outros programas internacionais, como o Food Stamps, dos Estados Unidos, e o Food for Education, de Blangadesh, que foram calculados na faixa 
de $30 \%$ a $42 \%$ e de $34 \%$ a $41 \%$, respectivamente. No Brasil, com dois anos de programa, a diferença média entre os gastos familiares com alimentos ( $\mathrm{R} \$ 24,53)$ é maior do que a média das transferências monetárias do programa ( $\$ 20,39)$. Assim, as PMCA foram estimadas em mais de $100 \%$, e notou-se uma mudança no padrão original de consumo, uma vez que as famílias passaram a destinar um parcela maior de seus demais recursos para a aquisição de alimentos.

\section{Consumo}

No período analisado, observou-se aumento de quase três itens alimentares por família beneficiária, sendo 24,2 itens nas famílias-controle (excluídas) contra 27 nas famílias com a complementação. Após 24 meses de transferência, a análise da correlação entre gastos por grupos de alimentos e composição da dieta de crianças de até dois anos de idade mostra que a distribuição intrafamiliar de alimentos é melhor entre as famílias beneficiadas, com maior variedade e maior valor nutricional dos alimentos.

\section{Antropometria}

Os dados antropométricos foram obtidos de 1.481 crianças após seis meses de transferência, e de 1.423 crianças após 24 meses, e não mostraram haver diferenças com significância estatística $(\mathrm{p}<0,05)$.

Os resultados da análise retrospectiva dos registros do Cartão da Criança indicam, contudo, diferenças estatisticamente significativas no padrão de ganho de peso por parte das crianças beneficiárias no período de 24 meses. Segundo as regressões realizadas com os dados antropométricos das crianças de até cinco anos de idade, cada mês adicional de recebimento da bolsa alimentação estava associado a um ganho de peso de $8 \mathrm{~g}$ a mais pelas crianças beneficiadas $(\mathrm{p}<0,001)$.

Também o indicador composto de gravidade e freqüência dos déficits nutricionais mostra que as crianças beneficiadas, inicialmente em pior situação, apresentam maior velocidade de recuperação, não havendo diferença, ao final do período de análise, em relação às crianças excluídas (Figura 1).

Entre os aspectos estudados, destacou-se o impacto sobre os indicadores econométricos, constatando-se a aplicação da maior parte dos recursos para a aquisição de alimentos e o aumento da variedade da dieta. A ausência de uma linha de base para os estudos pode ter limitado parte das análises, segundo as quais, aos seis meses, houve menor ganho de peso entre crianças de famílias beneficiadas do que entre as excluídas, situação que se reverteu ao final do período de investigação. Outro fator de confundimento pode ter sido o fato de as crianças dos dois grupos não serem completamente comparáveis no início, o que se nota por meio das análises de recuperação nutricional a partir dos dados do Cartão da Criança e da antropometria de campo.

Em outros países, a expectativa de queda nos indicadores de desnutrição também se confirma, como ilustra o Progresa mexicano, em que se observou aumento de $1 \mathrm{~cm}$ na estatura de crianças beneficiadas quando comparadas com 
não-beneficiadas, embora nesse caso houvesse também o uso de suplemento nutricional.

Ainda que com essas limitações, os resultados do estudo sobre o impacto do Bolsa Alimentação mostram o potencial promissor para o crescimento infantil e, conseqüentemente, para a desnutrição, que os programas de transferência de renda associados a condicionalidades trazem.

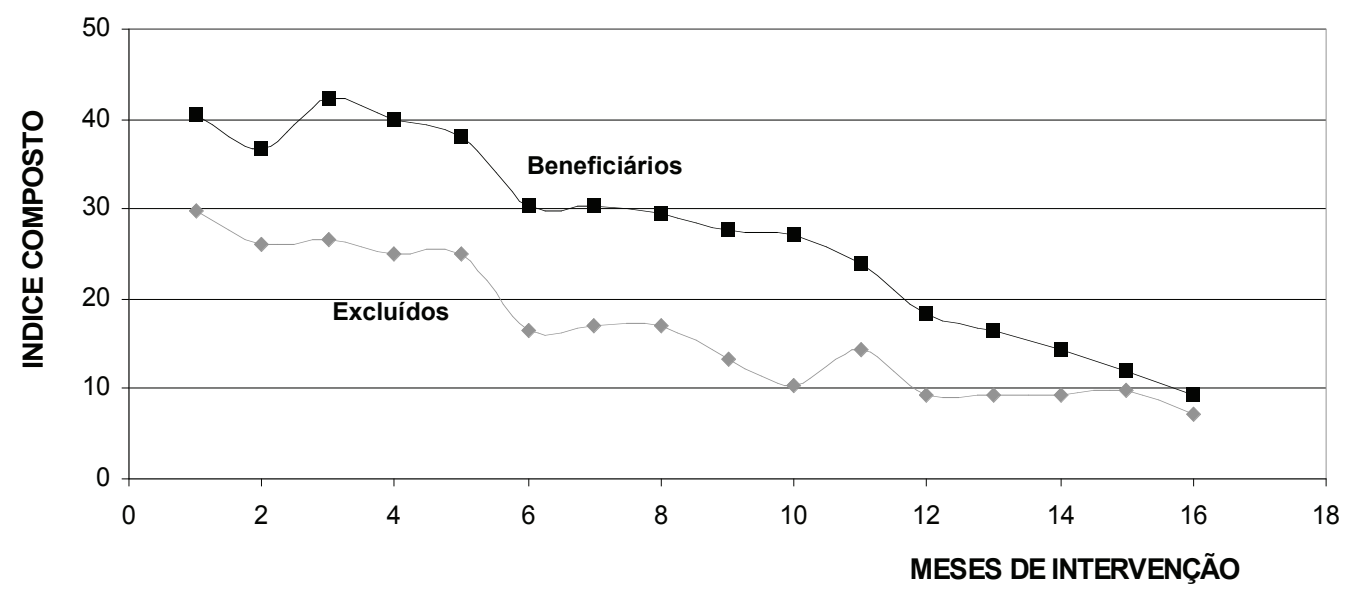

Figura 1

Evolução do indicador de gravidade e freqüência dos déficits nutricionais de crianças beneficiárias e não-beneficiárias do Programa Bolsa Alimentação de 2001 a 2003.

\section{Educação nutricional: o Programa "Eu aprendi, eu ensinei"}

O Programa "Eu aprendi, eu ensinei: uma prática de educação" foi concebido como parte da Formação de Programas de Cidadania Juvenil na Prevenção e Combate à Desnutrição Materno-Infantil, proposta pelo Centro de Recuperação e Educação Nutricional (Cren), da Universidade Federal de São Paulo (Unifesp).

Objetiva mobilizar e capacitar escolas de Ensino Médio para promover ações que contribuam para a prevenção e o combate à desnutrição infantil. Com financiamento do Ministério de Desenvolvimento Social e Combate à Fome, traz recente experiência de sucesso em 53 escolas da região norte do Estado de Minas Gerais; contou também com a participação da Secretaria de Estado da Educação de Minas Gerais e das superintendências regionais de ensino.

As premissas do programa tomam a escola como locus de mudança, como espaço público que contribui para a inserção do indivíduo na realidade que o cerca, por meio do exercício da verdade, do conhecimento de si mesmo e do mundo. Em segundo lugar, o programa está baseado na interdisciplinaridade como forma de reunificação do conhecimento. A terceira premissa é a formação do sujeito coletivo, entendido como um grupo de referência no qual é mantida a identidade dos indivíduos que o compõem. 
Finalmente, o programa estimula o protagonismo juvenil, favorecendo a participação do jovem como sujeito em ações que dizem respeito a problemas relativos ao bem comum.

\section{Indicadores da experiência em Minas Gerais}

A experiência no Estado de Minas Gerais resultou na capacitação de 53 professores do Ensino Médio, nove técnicos das superintendências regionais de ensino e nove profissionais da área de saúde. Foram aplicados os módulos de pedagogia, nutrição, serviço social e psicologia, e elaborados nove projetos que tinham por objetivo orientar as ações em nível local, além de um documento das superintendências regionais de ensino com proposta de atuação dos técnicos junto às escolas. A partir da ação dos 62 multiplicadores capacitados pelo programa, 1.251 professores foram mobilizados, e desses, 990 envolvidos pela capacitação local.

Os números dessa mobilização traduzem a apropriação do tema por professores e escolas em sua prática pedagógica. Em 67,6\% das escolas, o tema Nutrição e Saúde foi incluído no plano pedagógico depois do projeto, e 20,54\% delas se encontravam em processo de elaboração do plano. Quanto às ações relacionadas ao protagonismo juvenil, $65,7 \%$ dos alunos responderam afirmativamente a ações desenvolvidas na escola, e 63\%, na comunidade.

\section{Aspectos facilitadores e dificultadores}

Inúmeros fatores que influenciaram o desenvolvimento do projeto escaparam ao controle da equipe gestora. Entre esses, o período de realização das ações. É sabido que a dinâmica do trabalho escolar é regida pelo que se denomina período letivo e ano letivo. O projeto não pôde se valer, com liberdade, desse "tempo" escolar, ou seja, foi iniciado às vésperas do recesso de julho e, em um de seus momentos mais significativos para mobilização, deparou com as férias de final de ano.

O Projeto "Eu aprendi, eu ensinei" apresenta muitos indícios de sucesso, podendo sua metodologia ser reaplicada em outras situações que aspirem aos mesmos objetivos. Entre os aspectos bem-sucedidos estão:

a) professores mobilizados e comprometidos com o projeto, mesmo em um ambiente escolar nem sempre favorável a iniciativas desse tipo (trabalho voluntário desenvolvido além do período letivo, com gastos pessoais para a realização de ações);

b) alunos mobilizados e comprometidos com as iniciativas;

c) projetos de intervenção na realidade local sempre funcionando como "cartas de intenção" para ações e melhoria da qualidade de vida local;

d) incorporação no currículo da escola do tema Nutrição e Saúde e protagonismo juvenil;

e) aceitação do projeto pela Secretaria Estadual de Educação e esforço no sentido de lhe dar continuidade; 
f) avaliação positiva, seja quanto à proposta seja quanto à sua realização, por especialistas do campo educacional que tomaram conhecimento do projeto.

Um último, mas não menos importante fator deve ser pesado ao avaliarmos o êxito do projeto e a possibilidade de sua reaplicação em outros sistemas educacionais: o fato de ele ter sido desenvolvido em Minas Gerais. O sistema educacional mineiro é um dos maiores do Brasil, com capacidade crítica instalada entre seus educadores, de reconhecida presença histórica - haja vista a literatura sobre o sistema educacional mineiro e suas análises sobre o "gatopardismo na educação", isto é, sobre os mecanismos de efetivação de pseudo-reformas, que podem ser sintetizadas no lema "reformar para não mudar".

Outro aspecto a ser lembrado é que o "povo mineiro" é dotado de uma identidade cultural que o capacita, talvez mais do que outros agrupamentos nacionais, a emitir juízos comunitários com relativo consenso; ou seja, a adesão ou rejeição é mais grupal do que individual, diferentemente do que pode acontecer em grandes centros, nos quais a tendência é uma pulverização de identidades e não tanto a pluralidade e unidade em torno de valores constituintes de um ethos cultural.

Certamente, um projeto como o "Eu aprendi, eu ensinei" - com metodologia fundada no respeito absoluto a cada pessoa, na crença de que o ser humano possui desejos de humanização, de solidariedade e de partilha que, uma vez, mobilizados, podem colaborar para a melhoria da convivência em sociedade e, em conseqüência, da qualidade de vida humana coletiva - em muito contribui para a criação de uma nova ordem brasileira e universal.

\section{Experiências do setor privado: o Programa "Alimente-se bem"}

O programa originalmente chamado "Alimente-se bem com R\$ 1,00" foi concebido em 1999 pelo Serviço Social da Indústria (Sesi), em seu Departamento Regional de São Paulo. O objetivo central do programa é propor receitas econômicas por meio do aproveitamento integral dos alimentos e, assim, promover saúde e economia.

Programado para atender os trabalhadores da indústria e seus familiares, estendeu-se para a comunidade de maneira geral, dada a boa acolhida em diversos municípios não apenas do Estado de São Paulo. A motivação inicial do programa foi o resultado de um levantamento de consumo realizado com 1.600 trabalhadores da região norte do município de São Paulo: verificou-se inadequado fornecimento de nutrientes para $62 \%$ do grupo.

A proposta teve como fundamento a educação alimentar. Nutricionistas do Sesi iniciaram então o desenvolvimento de preparações com ingredientes de bom valor nutritivo e baixo custo, produzindo uma primeira publicação com as cem receitas que, quanto à qualidade sensorial, receberam melhor avaliação pelo público de eventos promovidos pelo Sesi.

\section{Estratégia do programa}

Com a finalidade de comprovar a viabilidade do preparo e a aceitação de 
pratos que continham partes de alimentos usualmente não aproveitadas, instalou-se em São Paulo, no bairro de Vila Leopoldina, o primeiro restaurante educativo, como unidade-piloto. Por um período experimental de noventa dias, esse restaurante serviu almoço, gratuitamente. Como houve aprovação de $98 \%$ dos avaliadores, após o período experimental o restaurante foi aberto ao público em geral, servindo refeição ao preço de R $\$ 2,00$ por pessoa. O custo da matéria-prima não ultrapassava $\mathrm{R} \$ 1,00$. $\mathrm{O}$ cardápio era composto por arroz, feijão, carne, guarnição, dois tipos de salada, pão, suco e sobremesa.

Para firmar o foco educativo do programa, em razão do bom resultado das avaliações, foram iniciados cursos práticos, gratuitos, oferecidos às famílias dos trabalhadores da indústria e à comunidade. $\mathrm{O}$ atendimento médio foi de quatrocentos participantes por mês, em turmas de 25 pessoas.

O sucesso do programa levou à abertura, no anos de 2000 a 2002, de mais oito restaurantes educativos, em diferentes municípios do Estado de São Paulo.

\section{Concepção dos cursos}

Os cursos são ministrados em quatro aulas com duração de duas horas e trinta minutos por aula, oferecidas uma vez por semana. São preparadas doze receitas do livro do programa. O conteúdo teórico inclui os seguintes tópicos:

- Definição do programa.

- Noções sobre alimentos e suas funções.

- Valor nutritivo dos alimentos.

- Planejamento de compras.

- Reconhecimento dos alimentos e cuidados no armazenamento.

- Higienização dos alimentos.

- Aproveitamento integral.

Em 2003 foi necessário investir na criação de cozinhas didáticas em 23 centros de atividades do Sesi-SP. A primeira cozinha instalada fora das dependências do Sesi foi a de Birigui, na sede do Sindicato dos Trabalhadores nas Indústrias de Calçados da cidade, por meio de convênio formalizado entre esse sindicato, o Sesi e o Sindicato das Indústrias do Calçado e Vestuário do mesmo município. Atualmente existem quarenta cozinhas didáticas. A partir de 2002, foram criadas seis unidades móveis, adaptadas em carretas, com capacidade para atender quatrocentos alunos por mês.

\section{Nova formatação dos restaurantes educativos}

\section{e parcerias para o aperfeiçoamento da proposta}

Atendidos os objetivos iniciais dos restaurantes educativos, em 2004 foi concluída a primeira etapa do Programa "Alimente-se bem com R\$ 1,00". A partir de 2005, o programa passou por modificações, mantendo porém sua finalidade principal, que é a educação alimentar. Os restaurantes educativos foram reestruturados, passando a denominar-se "cozinhas experimentais". Novos livros foram lançados, com mais receitas apresentadas de maneira atraente e ricamente ilustradas. 
Visando aprimorar o conhecimento sobre a utilização de partes não-convencionais de alimentos para a alimentação humana, em 2002 o programa firmou parceria com a Universidade Estadual Paulista (Unesp) de Botucatu, para o desenvolvimento da análise bromatológica de macro e micronutrientes dos ingredientes empregados nas preparações, como cascas e talos, a fim de garantir sua inocuidade.

Com uma equipe de 106 nutricionistas, o programa chama-se agora "Alimente-se bem" e caminha em parcerias de sucesso para sua ampliação. É um exemplo de como o setor produtivo pode contribuir com ações de educação alimentar e nutricional efetivas e de qualidade, constituindo-se como importante parceiro nas políticas públicas para a área.

\section{O papel da rádio comunitária no contexto das políticas públicas de saúde}

A comunicação é aqui tratada como um dos elementos centrais a serem considerados na execução de qualquer política pública, particularmente as de saúde. Com esse entendimento, pretende-se abordar a rádio comunitária como uma mídia de grande apelo no Brasil e no mundo, e que, por suas especificidades técnicas (o pequeno alcance, por exemplo), tem como principal característica promover a capilarização das políticas públicas.

Pretende-se mostrar a importância da radiodifusão comunitária nas ações educativas da área de alimentação e nutrição, partindo do princípio de que, para ampliar sua eficácia, é preciso ajustar as informações e as ações de modo que elas entrem em interação com os diferentes cenários sociais e culturais de cada território. Essa via de disseminação de informações não traz em si um modelo pronto de divulgação de questões relacionadas à saúde e à nutrição; é antes uma porta aberta, com grande potencial para contribuir com esse propósito.

\section{Considerações sobre comunicação de massa}

A cadeia de formulação de uma política pública - planejamento, execução, avaliação - deve incluir a etapa de divulgação, necessária para transferir à população beneficiária os elementos derivativos da política proposta e para compartilhar com ela o processo de avaliação ou de retroalimentação. Tomando como exemplo a pedra de Roseta, que traz gravada uma orientação religiosa em três idiomas distintos, ilustra-se um princípio básico da comunicação: a necessidade de inteligibilidade. Esse é um dos pressupostos fundamentais a serem considerados pelos responsáveis pelas políticas públicas.

A comunicação de massa deve ser compreendida como a transmissão de um conjunto de símbolos elaborados com base em princípios e valores de determinado grupo social para outro grupo populacional específico que vivencia valores sociais e culturais distintos. Por sua vez, cada indivíduo capta a informação de forma particular, dando a ela uma significação que resulta de sua história pessoal, de suas crenças e valores, bem como de sua instrução formal. Cada indivíduo e cada comunidade se apropriam da informação de uma forma peculiar. 
Voltando ao outro extremo, o termo massa institui, na origem, uma ruptura entre aquele que transmite, elaborador da informação, e o indivíduo que recebe - massa; aqui a transmissão e a recepção não mantêm o caráter dialógico da comunicação direta entre duas pessoas. Essa assimetria pode ser empregada a favor do objetivo da comunicação, a fim de mobilizar o receptor e, se possível, no caso em questão, estimulá-lo na alteração de comportamentos, isto é, auxiliálo a adotar práticas positivas de saúde.

Outras características devem ser consideradas pelos gestores ao pensar na utilização de uma "mídia de massa" como parte integrante do processo de implantação das políticas públicas: massa não quer dizer apenas quantidade, mas também pluralidade de receptores (domínio público e não-restrito); não quer dizer amontoado inerte, e sim pessoas específicas em contextos sócio-históricos específicos, com diferentes graus de compreensão e representação em suas vidas - a recepção como processo ativo; massa implica aumento da acessibilidade das formas simbólicas no tempo e no espaço.

Se pressupomos aqui a intencionalidade da informação em saúde, é preciso considerar que a gerência lato senso das informações nem sempre obedece a princípios democráticos, ou nem sempre está em sintonia com as necessidades da população. Ao contrário, a cartelização da informação, principalmente aquela veiculada em jornais e TV, torna-se evidente após a Segunda Guerra Mundial, quando as agências iniciam grandes acordos para organizar as pautas. Um exemplo: a Associated Press (AP) abriu mão de cobrir fatos na Europa para ter a exclusividade da divulgação de informações jornalísticas nos Estados Unidos. Os interesses jornalísticos se expressam no número de escritórios das agências, como mostra o Quadro 1. Não se percebem, nessa divisão, interesses baseados no processo de desenvolvimento ou em demandas sociais.

\section{Quadro 1}

Distribuição dos principais escritórios da imprensa internacional no período pós-Segunda Guerra Mundial

- Reuters 150 países

- AFP (Agence France-Presse)129 países

- AP (Associated Press)108 paises

- UPI (United Press International) 92 países

- 40\% dos escritórios na Europa

- 10\% na África, Oriente Médio e países em desenvolvimento

Fonte: Thompson (2002).

A mídia comunitária, pautada pelas necessidades de cada localidade, estaria na contramão desse movimento geral da imprensa e seria, portanto, potencialmente mais adequada à área da informação em saúde. 
Nesse cenário cabe valorizar os mecanismos de comunicação de interesse local, entre os quais se insere o serviço de radiodifusão comunitária, instituído pela Lei n. 9.612 de 19.2.1998.

\section{Contexto das políticas de saúde}

A vitória das oposições em 1986 nos pleitos estaduais estimulou o movimento de reforma sanitária e criou condições para que a Constituição de 1988 acolhesse as questões de saúde nos capítulos da seguridade social. A Constituição vai além: tomando como ponto de partida um conceito de saúde, amplia a ação institucional e revê toda a legislação relativa à promoção, à proteção e à recuperação da saúde. Com esse novo paradigma, a reforma sanitária brasileira foi pensada para operar em três eixos.

O primeiro, conceitual e doutrinário, concebe a saúde como uma resultante das condições de vida, e não apenas como ausência de doença; sua conquista se dá por meio de políticas econômicas e sociais que reduzem ou eliminam os riscos de agravos e também pelo acesso a serviços de saúde. Trata-se, portanto, de um equilíbrio relativo, com base territorial e vínculo temporal, e que necessariamente incorpora o outro lado da equação: a disponibilidade dos profissionais de saúde para acolher as necessidades da população. Inerente ao ajuste está a participação da comunidade, que deve ser compreendida em suas variadas formas e momentos, como na definição de prioridades, na defesa de direitos já atendidos ou, ainda, no esforço de ampliação das possibilidades operacionais do sistema de saúde.

O segundo eixo, político, concebe a saúde como direito de cidadania e atribui ao Estado o dever de provê-la "sem qualquer discriminação ou fatos condicionantes". Nesse sentido, não se pode deixar de reconhecer que a saúde está estreitamente relacionada à maneira com que o homem produz seus meios de vida (trabalho) ou satisfaz suas necessidades (consumo), estando ambas as dimensões no âmbito de responsabilidade das políticas de Estado.

O terceiro e último eixo, o estratégico-operacional, propôs a reorganização do sistema de saúde, estabelecendo como diretrizes a integralidade das ações de saúde, a participação e controle da sociedade e a descentralização, com comando único em cada esfera de governo.

É dentro desse novo contexto da descentralização que se avança no processo de municipalização, mas somente após a XVIII Conferência Nacional da Saúde, realizada em 1986, o Ministério da Saúde consolidará o papel do município na gestão da atenção à saúde. A reordenação do modelo assistencial parte da redefinição do papel das esferas federal e estadual e da viabilização de instrumentos gerenciais do município. São estabelecidas formas de controle e avaliação com base em indicadores epidemiológicos e vinculação dos serviços com os usuários, priorizando-se a participação da população. O território passa a ser conceito-chave da reforma sanitária e desse novo modelo.

Há, contudo, que precisar melhor o conceito. Existem pelo menos duas grandes correntes de pensamento que o elaboram de forma distinta. A primeira 
toma-o de modo naturalista, como espaço físico que está dado, completo. São os critérios geopolíticos que definirão um território, denominado território-solo. Nessa concepção, o entendimento da saúde sustenta-se no modelo da clínica. A segunda, coerente com a idéia de promoção da saúde como processo, vê o território como espaço em permanente construção, produto de uma dinâmica social onde se tensionam sujeitos sociais postos na arena política. O território ou os territórios dos municípios nunca estão acabados, mas, ao contrário, em constante construção e reconstrução.

\section{Rádio comunitária como veículo para educação em saúde}

Devem-se considerar alguns números ao avaliar a capacidade das rádios comunitárias como veículos para educação em saúde, tendo como referência as condições necessárias ao funcionamento de outros tipos de mídia, como o jornal impresso. O censo de 2000 mostrou que $13,3 \%$ da população entre quinze e 64 anos são ainda analfabetos, o que representa cerca de dezesseis milhões de cidadãos. A energia elétrica está em $94,8 \%$ das moradias, com média de iluminação nas casas de 40 watts, o que dificulta a leitura principalmente noturna (e não considerando, nesses números, os problemas de deficiência visual). Contudo, $99,99 \%$ da população têm pelo menos um aparelho de rádio em casa.

Segundo a Associação Mundial de Rádios Comunitárias (Amarc), existem hoje dezesseis mil rádios comunitárias (RC) no Brasil. Esse número é contestado pelo Ministério das Comunicações, que trabalha com oito mil. Já segundo a Associação Brasileira de Radiocomunicação Comunitária (Abraço), são trinta mil. Não há, portanto, consenso sobre os números, mas sabemos que são expressivos.

Um aspecto importante que deve ser levado em conta nas políticas de educação é o fato de que, entre os ouvintes e o comunicador dessas pequenas rádios, estabelecem-se laços diretos de confiança. Elas funcionam como emissoras FM de baixa potência, alcançando cerca de um quilômetro de raio a partir da antena emissora, e se vinculam à associação de moradores do local, sem relações ou patrocínios comerciais.

Exemplo de boa utilização dessa forma de comunicação é o trabalho desenvolvido pela Rede da Pastoral da Criança, que espalha mensagens em 1.600 RC. Outra estatística interessante vem dos cursos da Faculdade de Saúde Pública da Universidade de São Paulo (USP), que capacitaram mais de quatrocentas rádios comunitárias apenas na Grande São Paulo desde 1999.

Esses elementos, em conjunto, fazem da radiodifusão comunitária uma forma conveniente e ajustada territorialmente de informação de massa.

\section{Conclusões}

As conclusões da oficina de trabalho promovida pelo Grupo de Estudos Nutrição e Pobreza do Instituto de Estudos Avançados (IEA-USP) apontaram fortemente para a educação nutricional como prioridade entre os projetos estratégicos direcionados à reversão do atual quadro de convivência combinada entre desnutrição e efeitos da má nutrição. 


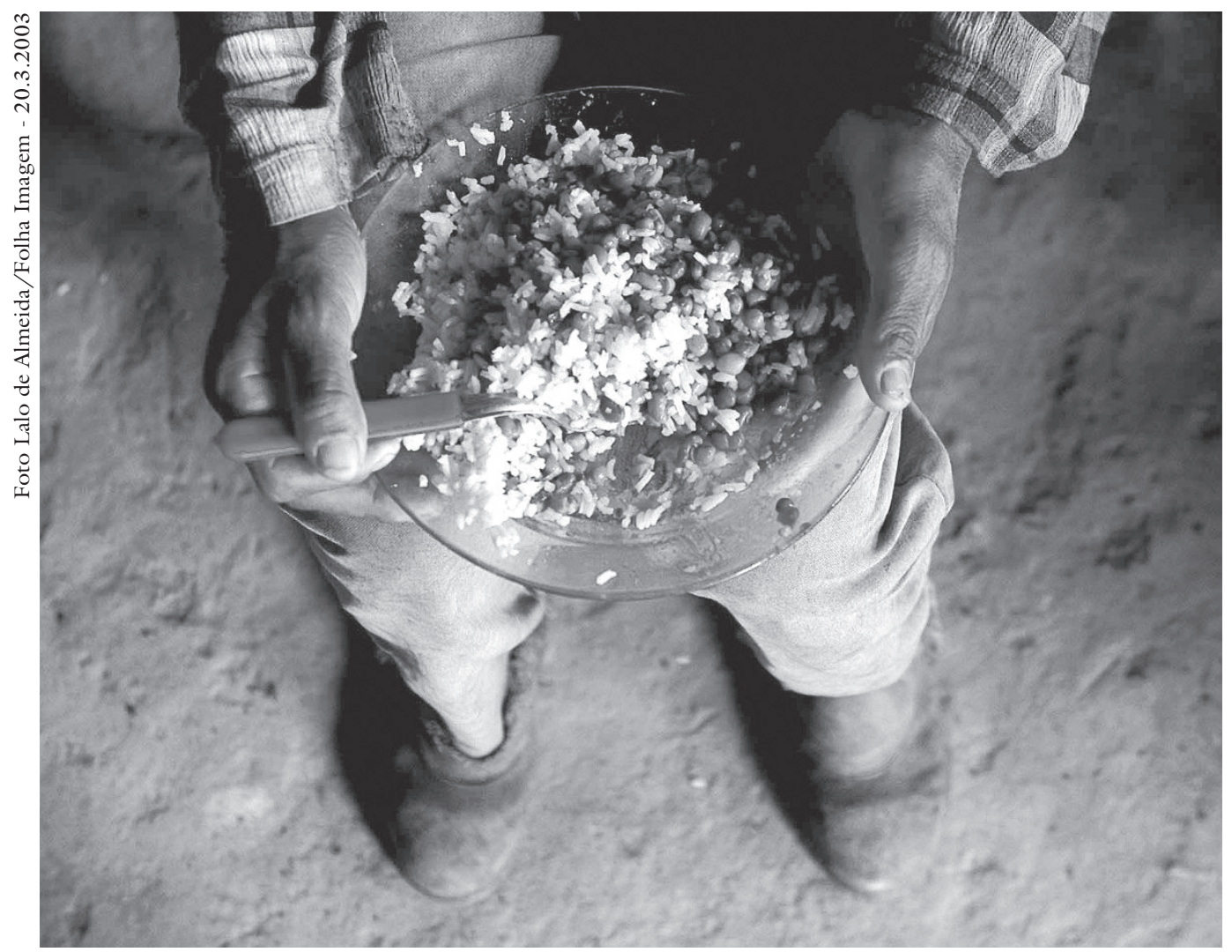

O agricultor Novasto Alves da Rocha mostra seu prato com arroz e feijão, em Guaribas (PI).

Este artigo relatou experiências de avaliação dos principais efeitos dessa convivência. Duas grandes ações do Estado - o Programa Nacional da Alimentação Escolar e o Bolsa Alimentação - mostram a importância do monitoramento da gestão para o trabalho de condução da política, a longo ou curto prazo. O PNAE, com cinqüenta anos de existência, passa por ajustes constantes, para adequar-se às novas demandas determinadas pela ampliação de sua cobertura e pelo avanço dos conhecimentos sobre nutrição e saúde. O programa de transferência de renda implantado indica melhoria no padrão de consumo de alimentos, especialmente por crianças de até dois anos de idade.

O relato das experiências educativas mostra como é possível implementar ações a partir do conhecimento das características loco-regionais do grupo a ser atendido, com resultados concretos de sucesso. O trabalho do Cren no Programa "Eu aprendi, eu ensinei" ilustra a importância da vivência para a apropriação de conceitos que propiciem modificação de comportamento e aquisição de boas práticas alimentares. O Programa "Alimente-se bem" é um exemplo de como o apoio do setor produtivo pode se traduzir em parcerias bem-sucedidas.

Por fim, discutiu-se o papel da mídia na educação em saúde, destacandose o potencial das rádios comunitárias para o propósito de estimular a adoção de estilos de vida saudáveis, entre eles aqueles relacionados à alimentação e à nutrição. 


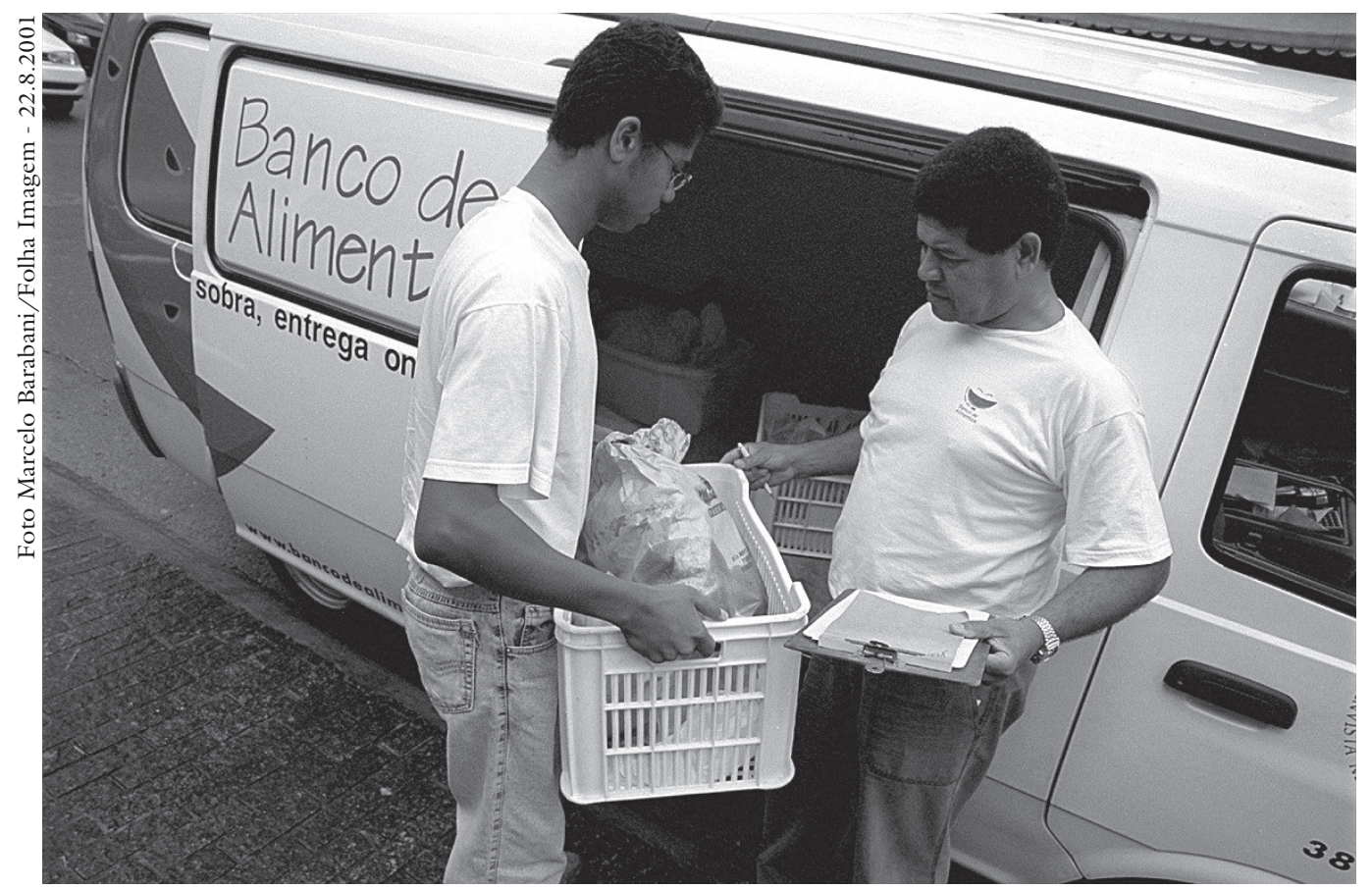

Técnicos da ONG Banco de Alimentos recolhem pães frescos de uma panificadora.

Nota

1 Diz o texto da Constituição Federal de 1988, em seu artigo 208:

"O dever do Estado com a educação será efetivado mediante a garantia de:

VII - atendimento ao educando, no ensino fundamental, através de programas suplementares de material didático-escolar, transporte, alimentação e assistência à saúde."

Referências bibliográficas

BURLANDY, L.; ANJOS, L. A. Acesso a vale-refeição e estado nutricional de adultos beneficiários do Programa de Alimentação do Trabalhador no Nordeste e Sudeste do Brasil, 1997. Caderno Saúde Pública, v.17, n.6, p.1457-64, nov./dez. 2001.

CAMPINO, A. C. C. Economia da alimentação e nutrição: noções básicas. São Paulo: Instituto de Pesquisas Econômicas da USP, 1985.

CASTRO, M. H. G. A política de combate à pobreza do governo do Estado de São Paulo. São Paulo Perspec., v.18, n.4, p.3-7, out./dez. 2004.

CASTRO, M. H. G. et al. Os desafios sociais no Brasil. Revista Conjuntura Democrática, Brasília, Fundação Astrojildo Pereira, 2004.

DOMENE, S. M. A. Indicadores nutricionais e políticas públicas. Estudos Avançados, v.17, n.48, p.131-5, maio/ago. 2003.

MAZZILLI, R. N. Nutritional value of the school lunch and its contribution to nutritional recommendations for preschool children, enrolled in the Center for the Education and Feeding of the Preschool Child. Revista de Saúde Pública, v.21, n.3, p.246-54, 1987. 
MUSGROVE, P. Do nutrition programs make a difference? The case of Brazil. Int. J. Health Serv., v.20, n.4, p.691-715, 1990.

OBORÉ. Projetos especiais em comunicações e artes. Disponível em: <obore.com>. Acessado em: 10 janeiro de 2006.

OMETTO, A. M. H. et al. Programa Nacional de Alimentação Escolar: principais componentes dos custos e seus determinantes. Nutrive, v.26, p.19-36, 2003.

RESOLUÇÃO/FNDE/CD N. 45 de 31 de outubro de 2003. Estabelecer critérios para o repasse de recursos financeiros, à conta do PNAE, previstos na Medida Provisória n. 2.178-36, de 24 de agosto de 2001, para o atendimento dos alunos da educação infantil e ensino fundamental matriculados em escolas de educação indígena.

RESOLUÇÃO/FNDE/CD N. 38 de 23 de agosto de 2004. Estabelece critérios para execução do PNAE (alterada pela Resolução n. 21 de 27 de maio de 2005).

SAVIO, K. E. O. et al. Avaliação do almoço servido a participantes do programa de alimentação do trabalhador. Revista de Saúde Pública, v.39, n.2, p.148-55, abr. 2005.

SPINELLI, M. A. S.; CANESQUI, A. M. O programa de alimentação escolar no estado de Mato Grosso: da centralização à descentralização (1979-1995). Rev. Nutr., v.15, n.1, p.105-17, 2002.

THOMPSON, J. B. Ideologia e cultura moderna. 6.ed. Petrópolis: Vozes, 2002 . p.22840 .

TORRES, H. G.; MARQUES, E. Políticas sociais e território: uma abordagem metropolitana. São Paulo Perspec., v.18, n.4, p.28-38, out./dez. 2004.

VASCONCELOS, F. A. G. Combate à fome no Brasil: uma análise histórica de Vargas a Lula. Rev. Nutr., v.18, n.4, p.439-57, jul./ago. 2005.

VELOSO, I. S.; SANTANA, V. S. Impacto nutricional do programa do trabalhador no Brasil. Rev. Panam. Salud Publica, v.11, n.1, p.24-31, 2002.

RESUMO - Medidas para o enfrentamento da fome e da desnutrição vêm sendo associadas a ações de prevenção dos efeitos da má nutrição, especialmente a obesidade e outras doenças crônicas, dado o aumento da sua prevalência. Esse quadro epidemiológico complexo exige a concepção de projetos estruturantes de médio e longo prazos ao lado de ações imediatas e criativas, para resposta a situações emergenciais quando da falta do alimento. Entre as propostas nascidas no setor público, no setor produtivo, em universidades e em organizações da sociedade civil, observa-se elevado grau de insucesso, a despeito da seriedade dos proponentes, levando à sua interrupção, com efeitos danosos para ambas as partes. Este artigo contém o relato de experiências de êxito, com elementos para a análise dos principais problemas comuns às políticas na área de alimentação e nutrição e formas de superação, e é o resultado do trabalho de pesquisadores, gestores públicos e técnicos que se reuniram em oficina interdisciplinar promovida pelo Grupo de Estudos Nutrição e Pobreza do IEA em 2005, cujo objetivo foi fornecer subsídios para o aprimoramento de políticas públicas na área.

PALAVRAS-CHAVE: Políticas de alimentação, Fome, Desnutrição, Abordagem interdisciplinar. 
ABSTRACT - Strategies to face hunger and undernutrition have been directly associated to actions to prevent bad nutrition effects, mainly chronic diseases and obesity. This complex epidemiological scenario requires initiative of medium and long-term projects, with simultaneously immediate and creative measures for emergency situations when no food is available. Among proposals initiated by the public and private sectors, by Universities and by non-governmental organizations, it is common to observe ineffectiveness, despite the commitment and integrity of the proponents, leading to harmful consequences to both community and the initiative. This paper contains reports of some well-succeeded experiences, including elements for analyzing the main problems common to food and nutrition sectors policy and ways of overcoming them. This work was produced by researchers, public policy makers and technicians as a result of the interdisciplinary workshop they attended in 2005. Offered by the Nutrition and Poverty Study Group of Advanced Studies Institute, São Paulo University, its goal was to subsidize the improvement of public policies in the area.

KEYWORDS: Nutritional policy, Hunger, Undernutrition, Interdisciplinary approach.

Semíramis Martins Álvares Domene é professora titular da Faculdade de Nutrição da Pontifícia Universidade Católica de Campinas. @ - semiramis@puc-campinas.edu.br

Rosana Rodrigues Lemes Ota é nutricionista da Escola de Saúde da Secretaria Municiapal de Saúde de Diadema (SP). @ - rosana.lemes@diadema.sp.gov.br

Eduardo Augusto Fernandes Nilson é biólogo, Coordenação Geral da Política de Alimentação e Nutrição/DAB/SAS/Ministério da Saúde. @ - eduardo@saude.gov.br

Miriam Izabel Simões Ollertz é nutricionista, Coordenação de Projetos, Centro de Recuperação e Educação Nutricional (Cren). @ - miriam@cren.org.br

Tereza Toshiko Watanabe é nutricionista, Diretoria de Alimentação, Sesi-SP.

@ - twatanabe@sesisp.org.br

Paulo Rogério Gallo é médico, Faculdade de Saúde Pública da Universidade de São Paulo (USP). @-prgallo@usp.br

Recebido em 22.5.2006 e aceito em 10.7.2006. 